\title{
The Impact of Information Technology Evolution on the Forms of Knowledge in Public Sector Social Work: Examples from Canada and the UK
}

\author{
Thomas M. Vogl \\ Oxford Internet Institute, University of Oxford, Oxford, United Kingdom \\ thomas.vog1@oii.ox.ac.uk
}

\begin{abstract}
In recent years, governments have been enthusiastic about the potential of digital changes to transform the way the public sector operates. While such changes were originally found to deprioritize the forms of knowledge needed by UK child protection workers, instead favouring administrative forms of knowledge, it was not known whether this impact was similar in other liberal democracies, nor whether this simply represented a phase in the evolution of digital government. This study explored this question through desk research and by interviewing and observing social workers as they interacted with a new information system. The study's findings suggest that while the experiences of social workers in a Canadian province replicate the previous $U K$ experience, current digital changes in the UK that are built on the earlier foundation may enhance the knowledge of child protection workers. These findings suggest that forms of knowledge may evolve with technological change.
\end{abstract}

\section{Introduction}

Governments such as those in Canada and the UK have been promoting the possibilities for more efficient and effective government made possible by digitization, data analysis, and artificial intelligence. In areas where street-level bureaucracy prevails, some have argued that shifts towards digital technology create a more informational approach to service, where the focus shifts towards gathering, sharing, and monitoring information about clients, worker decisions, and agency performance, and shifts away from the social, relational, and narrative aspects of service provision. This study explores whether there is a way to pursue greater levels of digitization while allowing front-line workers to maintain the narrative and social knowledge needed to carry out their frontline work. This study builds on trends identified in the
UK towards a more informational approach to services provision in social work, showing that similar trends exist in the child protection sector in the Canadian province of Ontario. However, examples of more recent technological changes in the UK suggest that the introduction of digital technology, supported by the previous wave of database technologies and informed by social work practice, could enhance the social and narrative forms of knowledge needed by social workers.

In what follows, the background and motivation behind digital change in government will be presented. Subsequently, an overview of theoretical perspectives will elucidate how digital changes are believed to shift social care professions from focusing on the social, relational, and narrative ways of knowing to the informational and administrative. The methodology sets out how these perspectives were studied in Canada and the UK. Previous findings from the UK indicate that the introduction of information technology (IT) shifted the focus of knowledge in children's social care from the narrative, social, and relational to a more database focused form of knowledge. Interviews and observation in Ontario indicate similarities, but have also shown how different groups expect different forms of knowledge from a new information system. Social workers seek to have knowledge that helps with frontline service delivery, system developers seek to have knowledge that aligns with the database structure of the system, and administrators seek to have knowledge that satisfies compliance, audit, performance measurement, and reporting objectives. More recent, but preliminary, evidence from the UK suggests that these forms of knowledge need not conflict, but that instead, through the design of applications, each one of these groups can have the knowledge they need to carry out their role.

\section{Background and motivation}

Since the beginning of the 2000s, governments in Canada and the UK have been pursuing e-government 
and digital government efforts [5, 30, 46]. Changes such as these have been touted as ways to fundamentally transform public service. This optimism has continued with governments more recently talking about the promise of digital strategies, data analysis, and artificial intelligence $[10,13,31]$, including their application to social policy [21].

Some of this momentum has transferred into the child protection sector. In the UK, some have suggested that " $[\mathrm{t}] \mathrm{echnology}$ offers the potential for professionals to share information more effectively, to make information more accessible, and to use systems to manage the workflow of children's services" [19]. Local authorities in the UK have a growing legacy of using information technologies to both deliver benefits to their residents and improve their efficiency when faced with austerity [20]. In this context, the Local Government Association indicated that "the rapidly changing technological and digital landscape, while doubtless a challenge, also offers many opportunities to implement innovative customer-focused approaches that deliver both improvement and efficiency" [20].

Similar aspirational language has been used around the introduction of and objectives for a new enterprise case management system called the Child Protection Information Network (CPIN) in the Canadian province of Ontario. The Ontario Ministry of Children, Community and Social Services has indicated that, through this new system, "[i]nformation to make the best decisions for each child will now be easily accessible to children's aid societies. They will be able to track what protection services children have received and the results, regardless of where in Ontario services were provided. The network will support timely and efficient service for kids in need of protection and their families" [6]. The Auditor General of Ontario has also shared this opinion, stating that "[t]hrough CPIN, the Ministry aims to enable timely sharing of critical child protection information among Societies, simplify administrative processes, and facilitate oversight through more timely, accurate and comparable service and expenditure data" [28]. However, while there have been years of technological change in both jurisdictions, some issues persist.

Despite initiatives to digitize and introduce new IT systems in the child protection sector, inquests into tragic child deaths have highlighted continued issues related to the information that is available for decision making [24, 25, 29]. A recent report of the UK House of Commons on Child Protection found that reforms to the system have been progressing slowly and that only $23 \%$ of services are rated as 'Good' by Ofsted [15]. In addition, in Ontario there is limited information about children served, their progress through service and life outcomes, raising questions about educational attainment, homelessness, youth justice involvement, and mental health outcomes [27]. The introduction of new digital technologies has not been a panacea for some of these problems. One potential explanation for this deficit is related to a shift in the forms of knowledge that are privileged in a new system.

\section{Theory}

There are numerous scholars who believe that technologies follow some progressive or modernizing trajectory [42]. A different group believes that social factors shape how technologies are interpreted and adopted [26]. These scholars believe that the social shaping depends on a constant negotiation of interpretations between groups around problems and solutions that different technological changes address [36]. Others have argued for a middle ground between technological determinist and social constructivist positions, suggesting that the affordances of technology set limits on the range of possible interpretations a technology can take [16]. In child protection services, researchers have found that information systems can set limits on what is possible for workers and that this can have implications for the forms of knowledge that are enabled by the systems. It is also possible that these limitations depend on the interpretations that different groups, such as developers or public administrators, have of the problems and solutions that a new system can address.

Nigel Parton argues that information and communication technologies have played a key role in reshaping the way that social work is done in the UK [35]. He argues that information technology has moved the focus of social work from the complex and relational to the categorical and informational and has thus shifted the type of knowledge in the field [35]. Parton believed that a more social approach was a means to overcome an assumption that deprivation was a determinant of future deprivation; however, it also required the construction of the subject, in this case the family, and the attribution of various characteristics [35]. This allowed social workers to advocate on behalf of the family, but it also made the family more knowable, calculable, and administrable [8, 35]. Within this context, technologies, including ICTs, "become a major influence in reconfiguring the form of knowledge itself" [35].

From the 1990s the focus shifted towards managerialism and performance auditing [14], and in response to a number of inquiries, there "was an increased emphasis on the need to collect, share, classify and store information" [35]. Information collection became less focused on the client's context and story and more about auditable administrative 
details such as their needs and level of risk. With this change, social workers began to feel as if the work was more administrative and less client focused [40, 49]. The privileged form of knowledge shifted as public administrators prioritized their reporting requirements in the design of the system, impacting the affordances of that technology for front-line workers.

Trust in the discretion of social workers was increasingly replaced by trust in systems. However, technologies themselves were not without flaws. Lord Laming in his inquest into the death of Victoria Climbié wrote that "the current state of the technology $\ldots$ is hampering progress. Professional practice and judgement ... are being compromised by an overcomplicated, lengthy and tick-box assessment and recording system. The direct interaction and engagement with children and their families, which is at the core of social work, is said to be at risk as the needs of a work management tool overtake those of evidence-based assessment, sound analysis and professional judgement about risk of harm" [19].

This tension has had a profound impact on the course of digitization and the expansion of the informational elements of social work. Parton goes on to explain that "[w]hereas previously, social work was primarily an oral and written set of practices which relied on the construction of narratives, increasingly, this is not the case ... This is not to say that the use of narratives is disappearing but that they are increasingly framed by the logic of the database." [35]. He suggests that "knowledge which cannot be squeezed into the required format disappears or gets lost." [35]. As a result, "the subjectivity and social context of the client can be deconstructed into a variety of lists and factors associated with, in particular, 'need' and 'risk'. Categorical thinking, based on the binary either/or logic, dominates, which puts individuals into categories and, in the process, obscures any ambiguities" [35]. Thus, "social work increasingly acts to take subjects apart and then reassembles them according to the requirements of the database." [35]. The IT preferred by social workers privileged forms of knowledge that would support service provision, and these typically took the form of narrative case notes. The IT preferred by public administrators and IT professionals privileged forms of knowledge, represented by structured data, such as drop-down menus and tick boxes, that would better support compliance, audit and performance monitoring. These forms of knowledge represent clients differently.

With a shift away from the types of knowledge needed by front-line workers to deliver their services effectively, some have suggested that "while public service agencies actively depend on the moral agency of street-level bureaucrats, they place these bureaucrats in working conditions that tend to undermine that very agency" [50]. Information systems that privilege forms of knowledge related to administration, compliance, and performance at the expense of narrative case-level information may cause workers additional administrative burden, rather than enhancing their ability to deliver effective services to their clients [19, 35]. However, there may also be technological tools to help street level bureaucrats build on the foundation of a database-oriented form of knowledge.

While the current state of information technology and data use may serve to undermine the forms of knowledge of street-level bureaucrats, it is possible that a different approach to digitization could enable the forms of knowledge needed not only to satisfy administrative reporting requirements, or the database logic of system designers, but to support effective front-line service delivery. Despite ongoing technological transformation in Ontario, the current outcomes do not appear to achieve this coexistence of administrative, IT, and service-level forms of knowledge. However, narrative, social, and relational knowledge enhancing technological changes may now be taking place in local authorities in the UK, building on the foundation set by the previous, more informational, period of digital change [47].

\section{Methodology}

This study compares cases of the evolution of digital change in the child welfare sectors of Canada and the UK $[7,9]$. The study first compares evidence from Canada to findings as reported by Parton. Subsequently, through document analysis of current technological initiatives in children's social care in the UK, it explores the possibility that digital change in the UK may be moving more towards a coexistence of administrative, IT, and front-line forms of knowledge.

In Canada, Ontario has implemented CPIN, a new case management system. It is a system that integrates data across all providers, permits the seamless transfer of data from one region to another, and supports backend administrative analysis of data [43]. This is a shift from independent legacy systems within social service agencies to an enterprise system developed centrally by the ministry. This system provides an opportunity to understand the impact of a centrally developed and delivered information system on social work practice. In the UK, local authorities have more holistic information about families, from aligned services in education, health, housing, children's social care, and adult social care, but that information might not travel as easily across regional boundaries. Some local authorities are taking advantage of their cross sectoral 
data holdings to pursue interesting projects in data analysis and decision support [3, 45]. Local authorities also have reporting obligations to central government [15]. A comparison of these cases with relatively similar child protection business practices, but different digital changes, can illuminate the informational changes in social work practice across the two jurisdictions [7]. Such a comparison can also allow for empirical exploration of the theory that forms of knowledge in social services change with the evolution in information technology [1].

Understanding the impacts of digital change from an organizational perspective demands more than just an exploration of the technology. Public administration is a socio-technical system, so efforts were made to study the interactions between people and technology. Since Simon [44], there has been a focus on behavior within organizations and its impact on decision making; however, a socio-technical understanding of administrative systems has been the subject of study since Weber [48]. In this study, the focus is on how the forms of knowledge used by different social groups are impacted by digital change. In both Canada and the UK, document analysis was used to identify historical details about the cases, identify potential interview subjects, and gain familiarity with the relevant concerns, concepts, and terminology used by practitioners [4]. In Ontario, purposive sampling was used to target individuals across functional areas who may have different experiences of a similar change.

Data were collected through document analysis, semi-structured interview, observation, and fieldnotes, similar to other studies in public administration, organizational studies, and the study of applications $[22,32,38]$. Interpretive approaches, such as this, have been shown to generate valuable public administration knowledge [2, 34, 38], as well as useful knowledge about information technology in organizations [33]. Semi-structured interviews and observation sessions with eleven participants in Ontario, from positions ranging from front-line workers and their supervisors to quality assurance (QA) staff, were conducted between July and November 2018. These sessions were recorded and later transcribed. In addition to publicly available documents, such as inquests, auditor general reports, conference presentations, and administrative documents, some participants shared internal documents related to the topics under study. Research in the UK was limited to document analysis due to challenges acquiring access in local authorities.

Fieldnotes were completed immediately after interactions. Data files were digitized and uploaded into NVivo for analysis, which followed an initial codebook that was revised to accommodate emergent themes and concepts that could not be easily categorized under those drawn from the literature [39]. This study follows a number of measures of quality in qualitative research, including ongoing peer debriefing and plans for archiving data, in order to ensure auditability, credibility, dependability, and confirmability in the research $[18,23,34]$.

\section{Findings}

\subsection{The informational context in the UK}

As noted in the theoretical discussion, there was a shift from social to informational forms of knowledge in the UK $[35,40]$. Samuel, for example, found in a survey of 2,200 social care professionals that ninetyfive percent felt "that social work had become more bureaucratic and less client-focussed over the previous five years" [40]. Further, studies of the Integrated Child System and the Common Assessment Framework in England, found that workers saw the tools as cumbersome, deskilling, and challenging of professional judgement [11, 49]. While these studies are limited to the UK, some have suggested that a similar process could be taking place in other liberal democracies [11].

\subsection{Evidence of replication in Canada}

In Canada, there appears to be a similar process at play, with the introduction of a new enterprise case management system in Ontario's child protection sector. Social care professionals have raised concerns about how they are experiencing the shift in the privileged forms of knowledge from a narrative record structure that supports service-level decisions, to a database focus where the work balance is weighted towards administrative documentation to meet standards for managerial compliance and performance monitoring.

One QA worker explained the difference between case notes, which were rich in information, but difficult to retrieve from the system and the check boxes and drop-down menus that were simple to retrieve, but that did not provide a great deal of narrative: "the contact logs [case notes], for example, they can have really rich narrative, but it's not something easily accessible ... it's not even accessible for downloading $\ldots$ and doing a content analysis ... So, then you're beholden to just dates [striking the desk], really dates [striking the desk again], and ticky tacky, tick boxes, and that can only get you really so far, if you're really trying to understand the work" (Participant 2, personal communication, 18 August 2018). Certain types of information related to 
compliance and performance are easier to retrieve than other types that are related to the narrative content of the records. The QA worker also noted that "CPIN is ... meant to measure whether something has been entered or not ... [However,] if you're really wanting to know whether something's working or not, or what somebody's doing or not, probably the worst thing you can do is just measure whether you see something entered or not, because you don't know the quality of that, or what's been done" (Participant 2, personal communication, 18 August 2018). The privileged forms of knowledge were related to a managerial demand for compliance to satisfy auditable standard operating procedures, rather than quality related to the specific contextual and relational features of the client's narrative.

The QA worker also raised a concern about the limitations on the types of information that can be found within the system, such as where structured fields are not present, explaining that for information about some work-related tasks, "it'd be like finding a needle in a haystack to try to identify this unless there was a protocol for how you document that type of interaction, which, you know, there is none of that. So, what ends up happening is that ... if that becomes a big chunk of your work, this kind of ad hoc, type of work, how do you measure it? Well, then you've got to put something in place to do that, and you can't use CPIN to do that ... there's the hurdles [to] doing it that are probably not worth it if you can do it somewhere else ... in a more efficient way" (Participant 2, personal communication, 18 August 2018). Certain types of information related to direct service provision cannot be collected in the system, and so social workers find ways to document this information outside the system.

A supervisor made a comparison with the previous system, which had supported a more narrative form of knowledge, saying that with CPIN, "we're struggling with how to keep our narrative because that's what we're used to as social workers, how to keep our narrative, but still have data integrity" (Participant 9, personal communication, 26 September 2018). Another supervisor emphasized the point about loss of narrative in the new system and described a new emphasis on performance, indicating that "there is a focus on that administrative component to get the recording done ... now it's very public, everyone sees and you just almost compete with each other in terms of ... compliance" (Participant 15, personal communication, 25 October 2018). The form of knowledge has shifted from one where the focus was on strengths and context of a family, captured through a predominantly narrative form, to one where the privileged form of knowledge is related to compliance and performance measurement.
There were also concerns around whether the system would be able to provide relevant and helpful insights to front-line workers. The supervisor explained, "I don't know if I feel like we're a sector that's the best at how a tool describes a family situation", going on to say that "that's the whole piece of us struggling with how is technology gonna fit in, like more of a puzzle piece" because "sometimes the descriptors or the conversations in a narrative of a contact log, [are] more helpful to me than a ticky box in a risk assessment" (Participant 9, personal communication, 26 September 2018). The fundamental issue of the database approach for the supervisor was that "having somewhere that you can quickly look, 'oh, is this case high ... risk, was it not high risk?', that might help with one part of a decision, but in the context of the entire family constellation and how that family actually functions, I think it would be unfair not to look at the narrative" (Participant 9, personal communication, 26 September 2018). This shows the distinction between the form of knowledge from standardized assessments and that found in narrative case notes and how, when it comes to decision making, front-line workers and their supervisors privilege knowledge from the case narrative because of the context it provides.

Many front-line workers shared similar experiences. One worker complained about the risk assessment tool that is currently in place, saying that "we have a document, the ticky box document that has a series of qualifiers that then lead to it determining whether or not a family is at high risk ... and I just think it's so ironic because look at how many times we're looking to close a case because we have done our investigation, we've completed our assessment, but yet the document shows high risk and we have to do a conference with ourselves and our supervisor in order to declassify that and explain why it's not high risk, and why we're contradicting what that document, or that tool is showing" (Participant 13, personal communication, 26 September 2018). The worker experiences that the risk assessment is privileged over the narrative and social knowledge held by the worker.

Another worker explained that "the most difficult job in the world is to deal with the human mind, or human behaviour" and did not believe that any tool could provide a universal approach to service, worried that under such an approach people who became embroiled in the system, whether client or worker, would be "subdued to a position where we are just ... objects" (Participant 10, personal communication, 26 September 2018). This illustrates how the database logic presents clients as administratively simplified and quantified objects of intervention rather than people in need of support. These two perspectives demand 
different forms of knowledge and support different kinds of decision making.

One front-line worker described how the system did not make sense to them, "the CPIN system ... it's not a rational system to me ... you have to know how to operate it to find where things are" (Participant 16, personal communication, 25 October 2018). This demonstrates how the database logic of the system did not align with the professional logic of social work, including how social workers would expect to store and retrieve information and what kinds of information they would expect to be readily available. Another worker expressed how the experience of moving to the new system was changing the expertise they were expected to have: "we've had to be more IT people ... since CPIN came in ... now you know way more than you even care to know about it" (Participant 19, personal communication, 20 November 2018). Social workers do not see the system as a tool that facilitates their work, they see it as something where they are expected to adopt the form of knowledge of different groups to meet IT standards or administrative reporting requirements.

Another worker described how the harmonization efforts undertaken by the CPIN training teams, in order to get all agency social workers inputting data into the system in the same way, began to come into conflict with the exigencies of the reporting requirements, which were often led by a different group of workers on the QA teams. This conflict arose because the way to document information so that it would be pulled by the reporting system sometimes differed from the documentation procedures needed for harmonization. The worker on a CPIN training team explained, "sometimes what [the QA team is] telling them, [is] just to get the results they want [and it] might be conflicting [with] what [we] really wanted to tell the staff as to how to put the data into the CPIN so that it meets the standard of using the product" (Participant 7, personal communication, September 25, 2018). The interpretation of the database logic differs based on the user group: workers seek a narrative case note structure, system trainers seek to follow the technical standards of use, and QA workers seek to ensure data is collected to facilitate reporting requirements. Each group demands a different form of knowledge.

One worker provided a comparison between their experience of service provision before the introduction of the new system and performance monitoring after: "I feel like social work has been watered down. I think that our primary goal is CPIN, completing, achieving the outcomes, and I don't mean social work outcomes, I mean data outcomes" (Participant 21, personal communication, 20 November 2018). The worker went on to describe their experience of performance monitoring: "I think now, CPIN adds the notion that you're being tracked ... I know colleagues in other branches that can say, 'oh, my supervisor talked to me about my stats this month', right. Whoa! Not your recording, they came to you about your stats" (Participant 21, personal communication, 20 November 2018). Another worker interjected, saying that the system is not concerned about "the relationships that you're building", instead, "it's about numbers" (Participant 20, personal communication, 20 November 2018). The other worker concluded, "it's about [the] system. It's not social work anymore" (Participant 21, personal communication, 20 November 2018). These workers shared a concern about how they experienced the priorities surrounding the system shifting from service provision to performance monitoring.

Finally, one worker provided an analogy for the administrative burden associated with the new system: "one of the issues that we're having is that ... if people recognize that there's so much more work to invest in CPIN, something's gotta give. You're only a human being and if you have [one] hundred percent battery, [and] more of the battery's going towards CPIN, what's happening with the social work piece? ... we have to give up something and it seems to be the casework" (Participant 21, personal communication, 20 November 2018). Another worker agreed, indicating that "it's moved a lot from working outside of the office with families to more administrative now" (Participant 17, personal communication, 25 October 2018). Workers perceive that the forms of knowledge demanded by the new system crowd out the form of knowledge needed to practice social work.

As social care workers in Ontario have indicated, their experience is that the introduction of a new system has shifted focus from the social and narrative knowledge needed to support front-line work, to informational and administrative knowledge. While these findings are based on worker experience and have not been quantitatively assessed to identify if the phenomenon is generalizable across the province, or across the different systems used across the country, it does indicate that a similar sentiment to that found in the UK exists among workers in Ontario [35].

\subsection{Evidence of evolution in the UK}

At the same time, it is possible that there has been a process of learning in the UK, which could eventually be replicated in Canada. Applications can be built on top of a database foundation that preserve database and administrative forms of knowledge and that may also be able to recover a more narrative and social form of knowledge for service provision. Document analysis has revealed three examples in the UK, including a 
prototype tool being piloted by the Behavioural Insights Team that does analysis based in part on structural topic modelling of worker case notes, a network visualization tool that presents a genogram with service involvement, and a dashboard that provides visualizations of quantitative measures. These examples represent applications that could enhance underlying database systems to help workers in different roles within the organization to recover a social work focus.

The Behavioural Insights Team has been working with local authorities and their children's services departments to identify if they can alleviate pressure on workers in the initial case assessment role. This role is one where workers must make quick or critical decisions "with scarce resources, under fierce time pressure and often in the face of hostile opposition" [41]. They are using techniques from machine learning and natural language processing to improve the rates of false positives (cases that were investigated but that were low risk) and false negatives (cases that were screened out, but that later came back). The prototype tool they developed uses a combination of structured and unstructured data, including worker case notes, to identify characteristics of cases that could potentially help to achieve these goals (see figure 1).

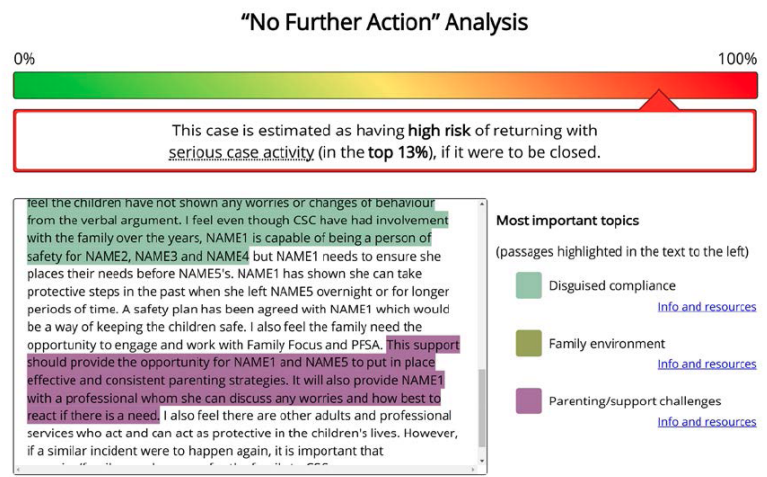

Figure 1: Design of the prototype children's social care risk assessment tool [41].

Work on the unstructured data involved finding key passages in case notes and taking those back to workers to understand if the topics identified made sense to them. The Behavioural Insights Team indicated that: "This was important for this project because social workers would need to understand the reasons behind the algorithm's suggestions for any particular case in order to combine these insights with their own expertise" [41]. This represents an example where the time pressures facing social workers are understood, information from many social workers is being brought together (their case notes) to help each individual social worker to make assessment decisions, and these social workers were involved in making sense of the text that was highlighted by the tool. In this example, the front-line knowledge of the social workers was used in combination with the knowledge residing within the database to develop an application that could translate the database knowledge into usable knowledge for front-line social work.

Members of the Behavioural Insights Team have also been clear to note that "it's very important that any kind of tool or decision aid that comes about as a result of this work is not used as a performance management tool, or anything to beat social workers about the head with because the moment you do that, then it starts to open the possibility that they will begin to game the predictions ... so the tool itself will not be making effective recommendations because it's being fed information that's designed to trick it" [3]. An effective knowledge translation, from a performance to a service focus, can reduce worker resistance to new types of information technology. While still a risk assessment tool, it relies to a greater extent on the narrative case notes of social workers and leverages their collective expertise. This could be seen as one way in which technology could shift the balance back towards knowledge for service from knowledge for compliance and administration.

Dynamic genograms are tools that present chronological service involvement in a visual way. They represent another application that could shift the balance from database back to social work knowledge. Manchester has developed an integrated database with an interactive front-end that workers can use to visualize a family, the connections between its members, and its members' interactions with services over time (see figure 2) [12].

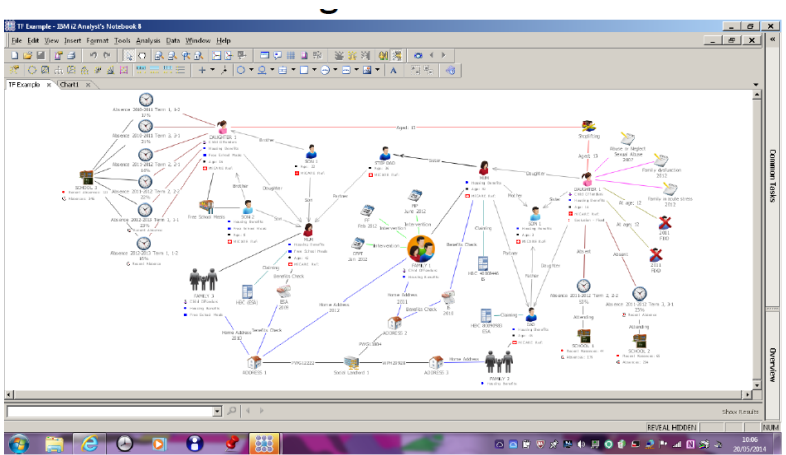

Figure 2: Screenshot of the visualization tool used in Manchester [12].

The use of genograms in social work practice is not new, but could be significantly enhanced by new digital technologies to put complex information in a visual form that can help social workers to understand the social and relational components of their cases [37]. This type of tool leverages digital technology to 
give social workers the information they need to carry out their social work role. It translates the informational knowledge from an administrative database into a form that presents sufficient context to support direct client service provision.

Dashboards for supervisors and managers to monitor service trends represent a third type of tool. Waltham Forest Council has begun to use dashboards to monitor performance [17]. While on the face of it, this may appear to privilege an informational approach, feedback on the tool resulted in comments such as, "[i]t shone a different light on our service information and thus provided us with analyses of our performance that are new to us and which present lines of enquiry that we may not otherwise be as proactively aware of" [17]. The tool, rather than being strictly used for performance related to compliance, was also able to highlight areas where people might be underserved, allowing potentially invisible people in need of service to be a part of the intervention. It took a database logic focused on administration (figure 3 ) and attempted to make it into a more narrative structure that can support strategic decisions about service (figure 4).

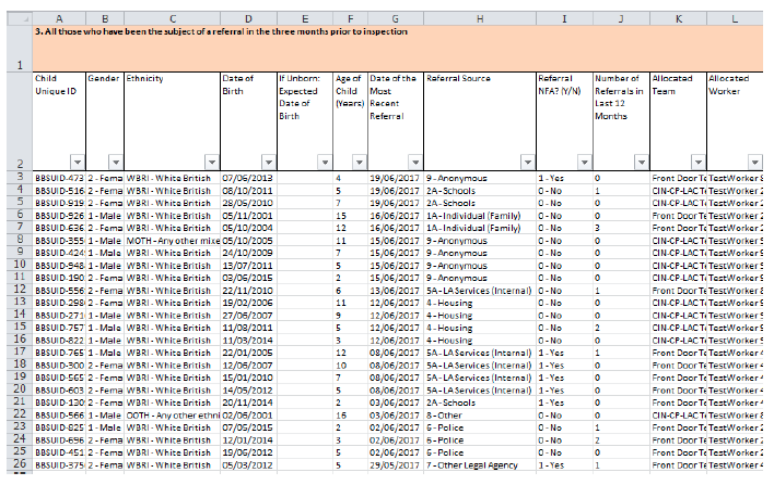

Figure 3: An illustration of raw data using a dummy dataset [17].

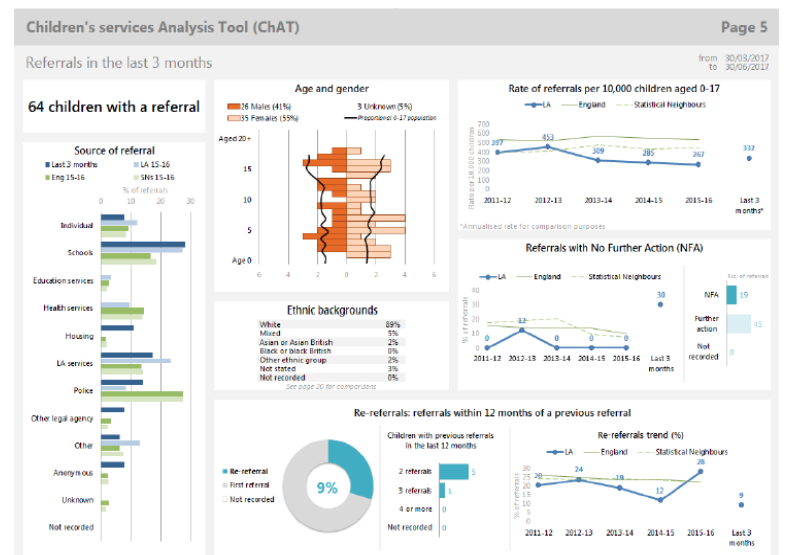

Figure 4: Children's service Analysis Tool [17].
These examples could demonstrate a technological shift towards knowledge that is more related to direct service provision. The limitation is that the present analysis in the UK involved only desk research and so the actual experience of the workers relative to these technologies and whether they experience them as social work supporting or simply more instances of an informational shift in the form of knowledge cannot be determined. Future research could look into the experience of workers when dealing with technologies that promise to enhance the forms of knowledge relevant to the social work profession.

\section{Analysis}

Previous literature has raised concerns about the move towards a more informational form of knowledge in social work, where data is structured by a database logic and is used more for management purposes of compliance, audit, administration, and performance measurement. It has also emphasized how these forms of knowledge would sometimes overwhelm the forms of knowledge needed for service provision.

Original research in Canada on the impacts of the introduction of a new enterprise case management system on front-line workers, their supervisors and QA staff, has identified similar types of concerns, illustrating how the forms of knowledge involved in IT system change may not be simply related to social or informational forms of knowledge, but may depend on the forms of knowledge privileged by the different groups involved and the extent of their roles in the design and development of the system. Based on this, it is possible that IT in itself is not to blame, but instead the degree of involvement of different groups with different privileged forms of knowledge in the design and implementation of the IT system. Examples in UK local authorities appear to indicate that efforts are being made to enhance the forms of knowledge needed for service provision in partnership with social workers. This may alleviate some of the stresses of their work environment, while at the same time preserving the forms of knowledge needed to support front-line service delivery. These examples, at the same time, seem to preserve the forms of knowledge related to IT and administration. These UK examples may represent an evolution in the progress of IT development in government from foundational database systems, that were seen to limit the forms of knowledge to the informational, to technologies that can build on these foundations and enhance the forms of knowledge, such as detailed narrative and contextual case notes, needed for front-line social work practice. 


\section{Conclusion}

If new digital applications can make data in an information system legible to front-line workers, then there is nothing necessary about changes in IT leading to an increase in administrative database knowledge and a reduction in the forms of knowledge needed for front-line social work. New technologies could just as easily enhance knowledge for front-line social work through user design, the development of project objectives, and social worker involvement. One recommendation for policy and practice is that in the development and implementation of IT change, the different forms of knowledge required by different user groups are mapped and aligned to ensure that the collection, storage, and retrieval of information by these different groups are not at cross purposes. These findings could potentially transfer to any sector that is administered, regulated, or overseen by the public sector and where there could be a tension between professional knowledge and knowledge needed for technology use, compliance, audit, and performance measurement. Future research could explore how different approaches to professionalization impact the forms of knowledge privileged by different groups and could identify how social work knowledge is shared with and interpreted by other sectors.

The informational forms of knowledge appear to remain prevalent with the introduction of new technologies. However, there may be opportunities for the narrative and the social forms of knowledge privileged by social workers to coexist with other forms of knowledge, depending on the digital change that is instantiated. In the absence of interviews and observation in the UK, it is unclear if this is the case. Further research would need to look at the actual impact of new digital tools that appear to be emerging in UK local authorities. However, if future research can identify whether workers understand the logic of their tools and are incentivized to keep up the integrity of their records, because doing so allows these tools to help them do their jobs, then perhaps the foundation will be set for public administrators, system developers, and social work professionals to benefit from both the informational and the social forms of knowledge enabled by digital change.

\section{Acknowledgements}

This research was supported by the Clarendon Fund and the Social Science and Humanities Research Council of Canada, Doctoral Fellowship number 7522017-0529. Research ethics approval was received from the University of Oxford with reference number
SSH OII C1A 18 055. I would like to thank everyone who took the time to participate in this research by agreeing to be interviewed or observed. I would also like to thank the reviewers for their insightful comments.

\section{References}

[1] Benbasat, I., Goldstein, D.K. and Mead, M. 1987. The Case Research Strategy in Studies of Information Systems. MIS Quarterly. 11, 3 (1987), 369-386. DOI:https://doi.org/10.2307/248684.

[2] Bevir, M. and Rhodes, R.A.W. 2003. Interpreting British governance. Routledge.

[3] Bright, J., Ganesh, B., Seidelin, C. and Vogl, T. 2019. Data Science for Local Government: Challenges and Opportunities. Oxford Internet Institute, University of Oxford.

[4] Brinkmann, S. and Kvale, S. 2015. Interviews: learning the craft of qualitative research interviewing. SAGE.

[5] Canada 1999. Speech from the Throne.

[6] Child Protection Information Network: 2016. http://www.children.gov.on.ca/htdocs/English/childre nsaid/societies/protection.aspx. Accessed: 2018-0403.

[7] Fitzgerald, L. and Dopson, S. 2009. Comparative case study designs: their utility and development in organizational research. The SAGE handbook of organizational research methods. D.A. Buchanan and A. Bryman, eds. SAGE.

[8] Foucault, M. 1991. Governmentality. The Foucault effect: studies in governmentality, with two lectures by and an interview with Michel Foucault. G. Burchell, C. Gordon, and P. Miller, eds. University of Chicago Press.

[9] Gil-Garcia, J.R. and Martinez-Moyano, I.J. 2007. Understanding the evolution of e-government: The influence of systems of rules on public sector dynamics. Government Information Quarterly. 24, 2 (Apr. 2007), 266-290.

DOI:https://doi.org/10.1016/j.giq.2006.04.005.

[10] Government of Canada 2018. Report to the Clerk of the Privy Council: A Data Strategy Roadmap for the Federal Public Service. Government of Canada.

[11] Hall, C., Parton, N., Peckover, S. and White, S. 2010. Child-Centric Information and Communication Technology (ICT) and the Fragmentation of Child Welfare Practice in England. Journal of Social Policy. 39, 3 (2010), 393-413.

DOI:https://doi.org/10.1017/S0047279410000012.

[12] Henry, S. 2016. Children's Social Care and Troubled Families. https://www.local.gov.uk/local-datavoresworkshop.

[13] HM Government 2018. Industrial Strategy: Artificial Intelligence Sector Deal. HM Government.

[14] Hood, C. 1995. The "New Public Management" in the 1980s: variations on a theme. Accounting, Organizations and Society. 20, 2 (1995), 93. 
[15] House of Commons, C. of P.A. 2016. Child protection: Thirty-first Report of Session 2016-17. Technical Report \#31. House of Commons.

[16] Hutchby, I. 2001. Technologies, Texts and Affordances. Sociology. 35, 2 (May 2001), 441-456. DOI:https://doi.org/10.1177/S0038038501000219.

[17] Jussa, R. and Mallo, J. 2017. Using Data Intelligently Waltham Forest Council.

https://adcs.org.uk/assets/documentation/AC17_Fri_E www.pdf.

[18] Klein, H.K. and Myers, M.D. 1999. A Set of Principles for Conducting and Evaluating Interpretive Field Studies in Information Systems. MIS Q. 23, 1 (Mar. 1999), 67-93.

DOI:https://doi.org/10.2307/249410.

[19] Laming, Lord 2009. The Protection of Children in England: A Progress Report. Department for Children, Schools and Families.

[20] LGA 2014. Transforming local public services using technology and digital tools and approaches. Local Government Association.

[21] LGA 2016. Transforming social care through the use of information and technology. Local Government Association.

[22] Light, B., Burgess, J. and Duguay, S. 2016. The walkthrough method: An approach to the study of apps. New Media \& Society. 20, 3 (Nov. 2016), 881900. DOI:https://doi.org/10.1177/1461444816675438.

[23] Lincoln, Y.S. and Guba, E.G. 1985. Establishing Trustworthiness. Naturalistic inquiry. Sage.

[24] Lord Laming, H. 2003. The Victoria Climbie inquiry. Stationery Office.

[25] LSCB Haringey 2009. Serious Case Review: Baby Peter. Local Safeguarding Children Board.

[26] MacKenzie, D.A. and Wajcman, J. 1999. The social shaping of technology. Open University Press.

[27] OAGO 2017. Child Protection Services ProgramMinistry Follow-Up on VFM Section 3.03, 2015 Annual Report. Office of the Auditor General of Ontario.

[28] OAGO 2015. Child Protection Services ProgramMinistry (Ministry of Children and Youth Services). Office of the Auditor General of Ontario.

[29] OCC 2014. Inquest into the Death of Jeffrey Baldwin: Verdict of Coroner's Jury: Verdict Explanation. Office of the Chief Coroner of Ontario.

[30] Ontario 1998. Using Information Technology to Transform Government for the 21st Century: Ontario Government Information \& Information Technology Strategy.

[31] Ontario's Government Launches Data Strategy Consultations | News Release: 2019. https://news.ontario.ca/mgs/en/2019/02/ontariosgovernment-launches-data-strategyconsultations.html. Accessed: 2019-06-09.

[32] Orlikowski, W.J. 2000. Using Technology and Constituting Structures: A Practice Lens for Studying Technology in Organizations. Organization Science. 11, 4 (Aug. 2000), 404-428.

[33] Orlikowski, W.J. and Baroudi, J.J. 1991. Studying Information Technology in Organizations: Research
Approaches and Assumptions. Information Systems Research. 2, 1 (Mar. 1991), 1-28.

DOI:https://doi.org/10.1287/isre.2.1.1.

[34] Ospina, S.M., Esteve, M. and Lee, S. 2018. Assessing Qualitative Studies in Public Administration Research. Public Administration Review. 78, 4 (Jul. 2018), 593-605.

DOI:https://doi.org/10.1111/puar.12837.

[35] Parton, N. 2006. Changes in the Form of Knowledge in Social Work: From the 'Social' to the 'Informational'? The British Journal of Social Work. 38, 2 (Oct. 2006), 253-269. DOI:https://doi.org/10.1093/bjsw/bcl337.

[36] Pinch, T.J. and Bijker, W.E. 2012. The Social Construction of Facts and Artifacts: Or How the Sociology of Science and the Sociology of Technology Might Benefit Each Other. The social construction of technological systems: new directions in the sociology and history of technology. W.E. Bijker, T.P. Hughes, T.J. Pinch, and D.G. Douglas, eds. MIT Press.

[37] Pope, N.D. and Lee, J. 2015. A Picture Is Worth a Thousand Words. The New Social Worker.

[38] Rhodes, R.A.W. 2011. Everyday life in British government. Oxford University Press.

[39] Saldaña, J. 2012. The coding manual for qualitative researchers. SAGE Publications Ltd.

[40] Samuel, M. 2005. Social care professionals overwhelmed by paperwork. Community Care. 14, 8 (2005).

[41] Sanders, M., Lawrence, J., Gibbons, D. and Calcraft, P. 2017. Using Data Science in Policy. Behavioural Insights Team. https://www.bi.team/wpcontent/uploads/2017/12/BIT_DATASCIENCE_WEB-READY.pdf.

[42] Schroeder, R. 2007. Rethinking science, technology, and social change. Stanford University Press.

[43] Shaw, R. 2014. B.C. alone in using troubled software system to manage child welfare. Vancouver Sun.

[44] Simon, H.A. 1976. Administrative behavior: a study of decision-making processes in administrative organization. Free Press.

[45] Symons, T. 2016. Wise Council: Insights from the Cutting Edge of Data-Driven Local Government. Nesta.

[46] UK Cabinet Office 1999. Modernising Government.

[47] Vogl, T., Seidelin, C., Ganesh, B. and Bright, J. 2019. Algorithmic Bureaucracy. Proceedings of the 20th Annual International Conference on Digital Government Research (New York, NY, USA, 2019), 148-153.

[48] Weber, M. 1968. Economy and society: an outline of interpretive sociology. Bedminster Press.

[49] White, S., Wastell, D., Broadhurst, K. and Hall, C. 2010. When policy o'erleaps itself: The 'tragic tale' of the Integrated Children's System. Critical Social Policy. 30, 3 (Jul. 2010), 405-429. DOI:https://doi.org/10.1177/0261018310367675.

[50] Zacka, B. 2017. When the state meets the street: public service and moral agency. The Belknap Press of Harvard University Press. 